\title{
A Critical Analysis of the Computer Graphic Art of Japan Using Six Case Studies
}

\author{
Jean Ippolito
}

\author{
Introduction
}

In studying art, historians sometimes look at a body of art work of a particular time period or geographic area seeking stylistic similarities. If similarities are found, they attribute them to various reasons or causes. When approached by the term "Japanese Art," one might conjure up images of Edo period wood block prints or Kamakura period ink paintings. Much of the art of Japan today, however, does resemble these ancient classics. Words like "diverse" or "eclectic" might adequately describe the contemporary Japanese art scene. When seeing the diversity of art work produced by Japanese artists, it is interesting to speculate on whether or not there is a "style" in computer graphics that can be described as "Japanese." Are Japanese cultural influences evident in this art?

Not enough is known about Japanese computer graphics in the United States. Because of the lack of knowledge about the content of the artwork and the context in which it is produced, harsh generalizations are made about the computer art produced in Japan. I have heard comments that Japanese computer animations have no substance and that they are only technically finessed. I was told early on that research on computer graphic art in Japan would not be worthwhile because of its lack of innovation.

I see the computer animations of Japanese artists as a reflection of postmodern Japan where the traditional is embedded in the new. Through interviews with artists and critical analysis of their artwork, I would like to add to our knowledge of recent Japanese computer art.

\section{Methodology}

In this study, six individual computer graphic artists of Tokyo are selected as case studies to represent the richness and variety of computer graphic art from Japan. Taped interviews are conducted to investigate each artist's ideas, background, possible influences, perceptions of their own work, and personal philosophies on computer art. The artists' studios and working environment are observed and documented photographically and by journal. Computer animated films, stills and other art forms, are solicited from each of the artists for study. The artists' published works and personal catalogues are also examined. Their works are reviewed using the 
descriptive, interpretative, and evaluative methods of art criticism explained by Terry Barrett in Criticizing Photographs: An Introduction to Understanding Images (1990). Emphasis is placed on description and interpretation with the understanding that the artists for this study were selected on the basis of their merit.

The interviews and observations will provide information from the artists' own personal perspective and from his or her own environment. The literature review will provide information from scholars and specialists of the field concerning Japanese culture and society in the artistic atmosphere of contemporary Tokyo where these artists reside and work. Furthermore, the chronological development of the artworks is documented and used to relate the content of the individual works to the artist's intent.

\section{The Artists}

Yoichiro Kawaguchi was born on the island of Tanegashima in 1952. He graduated from Kyushu Art and Design University with a major in Image Design in 1976. He graduated fro the masters program at Tokyo Education University in 1978. He was a professor at Nippon Electronics College in Shinjuku-ku, Tokyo, until April 1992. Currently he is Associate Professor in the Department of Art at the University of Tsukuba in Ibaraki Prefecture.

Kawaguchi is a "Renaissance" artist in that, his interest lies in the area of scientific discovery. The creation of a growth algorithm which stimulates the growth patterns of plants and animals found in nature launched him into intemational fame in 1982. Kawaguchi's more recent abstract computer generated animations have evolved from that growth algorithm. Major turning points in his stylistic development are Growth:Mysterious Galaxy 1983 (scientific fiction type surrealism), Morphogenesis 1984 (shows new technological developments which allow flowing organic shapes), Eggy 1990 (very liquid and abstract), and Metropolis "Cell" 1993 (dark metallic colors and a change in algorithm). Kawaguchi's development toward abstract expressionism is evident in a chronological overview of his work.

Ryoichiro Debuchi was born in Tottori prefecture in 1958 and graduated from Kyushu Arts and Design University with a major in Image Design 1984. He worked for two years at Tokyo's ASCII Corporation, and now he works for High Tech Lab, Japan, a soltware and CD production company in Tokyo. Debuchi claims to be influenced by Yoichiro Kawaguchi. His work, however, includes some narrative elements, sometimes using a poem or story from Western literature as the basis of his animations. Debuchi

Marilyn Zurmuehlen's Working Papers In Art Education 1994-1995 
values the randomness or unexpected character of the computer. He feels that this is the next step in a long series of art currents which sought randomness as a form of personal expression. These began with the Surrealists which influenced Dadaism and gradually found expression through machines in kinetic and technical art. Debuchi also feels that Guzen, or randomness has paraliels in traditional Japanese aesthetics.

Masaki Fujihata was born in Tökyo in 1956. He graduated from Tokyo National Arts University Department of Design in 1979. In 1982 he participated in the founding of SEDIC Corporation. In 1985 he established Frogs, Inc. Currently he is Associate Professor in the Department of Environmental Information at Keio University's Fujisawa Campus.

Fujihata is a concept artist. He begins with an idea and creates a series of works based on that concept. Each series is different from the next. Different output methods also influence variation in his style; i.e., animations, stills, stereo lithographic sculptures, etc.. Fujihata's work can be very philosophical, with undercurrents of meaning, or it can simply be an expression of his personal reaction to something. Much of his work is a pun, a joke, or a comment on the state of the arts. He often creates a computer algorithm with which to express his concept visually. The algorithm is the expression, and the output is the result. He feels, as an international artist, that he is no more influenced by Japan than an American or European artist living outside of Japan.

Naoko Motoyoshi was born in Tokyo in 1961. She worked for ASCII Corporation and High Tech Lab, Japan. Now, she teaches illustration at Chiyoda institute of Art and Technology. She also does contract work for NHK Television and the Shiseido Corporation. Motoyoshi's animations and stills are usually composed of traditional Japanese imagery.

Her work is impeccably crafted and beautifully composed. Some of it is considered by other artists as cliché; for instance, kimono-clad, doll-like figures with butterfly wings fluttering through groves of cherry blossom trees. Two years ago, Motoyoshi did a series of abstract stills entitled Acid Rain. She said that she wanted to produce some work which made a personal statement. Soon afterward, public demand encouraged her to return to her previous style.

Naoko Tosa teaches computer graphics and video art at the Universal Electronic Media Education Institute in Machida, and at Musashino Fine Arts University. Although she has been prolific as a video artist for some time, her recent computer interactive work Neuro Baby has catapulted her 
into international fame. Neuro Baby is a collaboration between Tosa and the engineers at Fujitsu Corporation. I t is based on an algorithm that detects pitch and mood in the human voice. A computer generated image of a baby's face, reacts in various ways to people's voices as they speak into a microphone. Tosa is a good example of a woman artist from Japan that focuses on the algorithm as expression, and does not fit the expected female stereotype.

Ikuro Choh was bom in Fukuoka in 1950. He graduated from Tama Fine Arts University in Graphic Design. Currently, he is an associate professor at Tokyo Zokei (Constructive Arts) University, and he is completing a Ph. D. Degree in graphic design at Tokyo National Arts University.

Choh says that his knowledge of "fine art" is limited, because he is a "designer." In fact, he often does commercial work on a contract basis. Much of his computer graphic art wok utilizes traditional Japanese imagery such as kanii characters, torii gates, and bamboo. He once created a series of scrolls in the format of Heian emakimono by feeding Japanese washi paper into a dot matrix printer and printing various traditional Japanese images juxtaposed with 3-D geometric forms and computer programming script. Choh feels that the Cartesian Coordinate space used to generate 3-D graphics is based on Western Renaissance perspective, and that he would like to create a computer algorithm which is capable of expressing a more traditional Japanese aesthetic.

\section{Context}

\section{American Views of Contemporary Japanese Art}

The following three major exhibitions of Contemporary Japanese art in the United States illustrate varied interpretations of contemporary Japanese art as portrayed in American museums in the last decade:

A Primal Spirit: Ten Contemporary Japanese Sculptors L. A. County Museum of Art and the Hara Museum, 1990: Focused on ten sculptors who use natural materials and themes of growth, change, evolution and decay.

Against Nature: Japanese Art in the Eighties, MIT List Visual Arts Center and the Cincinnati Contemporary Arts Museum, 1989: An exhibition about artists who work against common assumptions about Japanese art. 
Tokyo: Form and Spirit, 1986, Walker Art Center, Minneapolis: A commissioned collaborative exhibition focusing on technology and design in Japanese art.

The above are three very different exhibitions--all paint an honest portrait of some aspect of contemporary Japanese art. Each exhibition is curated from a different perspective. Some of these exhibitions were criticized for creating stereotypes of Japanese art.

\section{Identity Crises, the fear of stereotypes in Japan}

Many contemporary artists in Japan fear being labeled "Japanese." They prefer to be known simply as international artists. Their anxiety comes from the fear of being associated with cliché images of Mt. Fuji, Samurai, and Geisha--images that Americans often think of when referring to Japanese art.

\section{Conclusions}

Compared to some of the fine art computer animations produced in the United States, Japanese Computer animations lack the structure of traditional storyboard preparations. Rather than the narrative quality of traditional Western animations, they consist of surreal, train-of-thought type imagery. They have a vague atmosphere or creative environment in which imaginative creatures appear, rather than a clear political or social message. Since Japanese computer art animations often draw on Western subject matter or styles, it is difficult to separate the two into distinct categories.

Of the many currents within computer graphic art from Japan, two styles stand out, and sometimes conflict with one another. I call these the "expressive" and the "narrative" styles. The artists of the former category usually create a computer algorithm as a form of personal expression, and the computer graphic imagery that results from that algorithm form the primary elements of their artwork. The latter category, the "narrative" style, is imagery carefully planned by the artist belore execution, and beautifully crafted in result. Animations are usually constructed using a storyboard script. They follow a logical sequence from one scene to the next, with a beginning, a climax and an end. They are often well edited, and sometimes produced by "designers" or artists who work for production companies. Often, the works in this latter category incorporate traditional Japanese imagery, which may give an international audience the impression of a "Japanese style." Ironically the storyboard production method, and it's logical build up of a sequence of events from beginning to end, is probably more of a Western influence, and may also result from an effort to produce work that appeals to a general

Marilyn Zurmuehlen's Working Papers In Art Education 1994-1995 
intemational audience. The assimilation of traditional imagery combined with Western working methods in a High-Tech format is exemplary of postmodernism in Japanese art.

On the other hand, the "expressive" style is intuitive rather than logical. As animation, it is sometimes criticized for its disjointed leaps from one scene to the next, or one concept to another, with no beginning, climax or end. The expressive style may, in fact, be more closely related to traditional Japanese forms of expression in which personal style evolves unconsciously from the artist's knowledge and practiced familianity with technique.

It is my opinion that the look of Yoichiro Kawaguchi's work is clearly Western (like abstract expressionism), but it also has the influence of Oriental thought in its deeper meaning of evolution and change. In contrast, works like Namigaeshi of DaiNippon Printing Company are clearly Japanese from the traditional imagery, but also have the influences of the West in their logical storyboard production methods.

I have found some parallels between Japanese computer graphic art and contemporary Japanese sculpture. Similarities are found in artist's interest in nature, natural growth, unconscious growth, change, evolution, decay, etc.. There are also similarities in artist's approach to form and space. Like other forms of contemporary art in Japan, there is rarely a political or sociai narrative. Differences can be found in the overall complexity of computer graphics when compared with the simplicity of form and materials in contemporary Japanese sculpture.

A more concrete example of parallels between the two can be found in the expressive style of Yoichiro Kawaguchi. His growth algorithm uses two simple geometric shapes that are generated by the computer to build organic forms which evolve within an imaginary environment (the computer's Cartesian Coordinate space). New forms evolve by randomly changing the variable parameters of the program. The contemporary Japanese sculptor Takamasu Kuniyasu, like Kawaguchi, uses two simple building blocks to 'grow' his installation pieces. Kuniyasu's primary elements are tree branches and bricks. He stacks these, one by one, in an intuitive fashion to form an installation within the space of a gallery. When working in this way, he claims to go into a kind of "meditative overdrive" which contributes to the random evolution of his work. Another contemporary Japanese sculptor, Tadashi Kawamata who lives in New York, creates installation pieces using scraps of lumber as his primary building blocks. These are assembled, sometimes with 
the aid of assistants, to alter the form and space both inside and out of existing buildings.

Both of these sculptors create different versions of their installations by variations on the same building blocks with the same working manner. The artists' method of building an installation is their "algorithm."

Is there a Japanese style in computer graphic art?

There is no one Japanese computer graphic art style because the computer is a medium. As a medium, it influences "style," but since artists work in various styles, variety can also be found in the computer art of Japan.

\section{Postmodernism and Computer Graphics in Japan}

The computer graphic art of Japan, like contemporary Japanese sculpture, has a rich variety of influences. Computer graphic art is a mixture of modern electronic media with contemporary as well as traditional ideas. It is an example of the tensions and balance between high technology and tradition, the old and the new, the indigenous and the international in postmodern Japan. 